\title{
TRIBUS URBANAS: ENTRE RITOS Y CONSUMOS. EL CASO DE LA DISCOTEQUE BLONDIE
}

\author{
CHRISTIAN MATUS MADRID*
}

\section{INTRODUCCIÓN}

EL PRESENTE TEXTO CONSTITUYE un primer acercamiento a la subjetividad juvenil vista desde el prisma de las tribus urbanas. Este ensayo se encuentra basado en la experiencia de investigación realizada por el suscrito durante agosto de 1995 y diciembre de 1997 en torno a los grupos de jóvenes que concurren a la Discoteque Blondie ubicada en el sector poniente de la ciudad de Santiago. ${ }^{1}$

A modo de contextualización de nuestra exposición realizaremos primero una breve aproximación a las concepciones teóricas que dan origen a la noción de tribus urbanas y a su aplicación por parte de los estudios de juventud. Posteriormente presentaremos de qué forma este fenómeno global ha sido actualizado desde Chile distinguiendo los principales formas de agrupación juvenil susceptibles

* $\quad$ Antropólogo Social, Universidad de Chile.

1 Nuestra forma de abordar el estudio consistió en la implementación de una estrategia de investigación cualitativa que combinó el uso de la técnica de observación participante con la aplicación de entrevistas semi-estructuradas a 16 jóvenes de sectores medios-bajos, medios y medios-altos que asisten y participan en las «fiestas alternativas» que se realizan en la discoteque. 
de ser leídas como «tribus urbanas» y profundizando en una de ellas relacionada con el consumo de estilos juveniles vinculados a la cultura del rock. Es a partir de la exposición de este estudio de caso, que el presente artículo intentará dar cuenta desde una perspectiva antropológica, de cómo un grupo de jóvenes de diferentes sectores sociales que se reúne cotidianamente en una discoteque del sector poniente de la ciudad de Santiago construye un espacio de pertenencia e identificación a partir del consumo cultural de ciertos bienes y símbolos asociados a la cultura del rock, espacio de identificación que es posible asimilar a lo que en otras latitudes y estudios se ha dado por entender como «tribus juveniles» 0 «tribus urbanas».

Para cumplir con este objetivo, desarrollaremos primero una descripción etnográfica de este grupo y de una de las acontecimientos más representativas que agrupan a esta tribu como son las denominadas «fiestas alternativas». Finalmente, expondremos a partir de nuestra experiencia de campo, una síntesis de los códigos en torno a los cuales pensamos se articula la existencia de ésta y otras tribus urbanas en la ciudad de Santiago de Chile.

\section{TRIBUS URBANAS Y MUNDO JUVENIL: BREVE APROXIMACIÓN CONCEPTUAL}

En primer lugar partiremos por constatar que la idea de lo tribal o de «neotribalización» es una perspectiva de análisis que trasciende el campo de estudio de lo juvenil y se constituye como una reflexión más amplia respecto a los efectos y los cambios que generan a nivel de las relaciones sociales los procesos de globalización. Es en relación con un contexto de cambio sociocultural marcado por la tensión entre la masificación y el desarrollo de microgrupos o «tribus» que podemos comprender la emergencia de las «tribus urbanas» como nuevas formas de agrupación juvenil en las ciudades latinoamericanas.

Siguiendo los postulados de Michel Maffesoli, la transformación que la Posmodernidad (o segunda modernidad) opera en el tejido social produce una sustitución de principios y mecanismos tradicionales que antes marcaban la forma de relacionarse de los sujetos. Se produce un tránsito de un eje de relación a otro:

- de la importancia de la organización políticoeconómica, pasamos a la importancia de las masas.

- del sentido del individuo — establecido según la función— se pasa a la persona —rol—. 
- y de los grupos contractuales pasamos a las tribus afectivas.

Esta transformación en las relaciones sociales es la que Maffesoli define como neotribalismo emergente que hace que el sujeto salga de su encapsulamiento en la individualidad y diluya su experiencia cotidiana en la pertenencia a diferentes microgrupos o tribus. Las características de estas tribus serían:

i) Por un lado, constituirse en comunidades emocionales que se fundamentan en la comunión de emociones intensas, a veces efímeras y sujetas a la moda. Son agrupaciones constituidas por individuos que se reúnen y visten una estética para compartir una actividad y una actitud que genera sensaciones fuertes y confiere sentido a una existencia en donde en su cotidiano hay falta de contacto y contagio emocional.

ii) Oponer energía a la pasividad e hiperreceptividad del individuo de la sociedad de masas, constituyendo una fuente fragmentada de resistencia y prácticas alternativas, una energía subterránea que pide canales de expresión. Ejemplos: eventos deportivos, recitales, espacios festivos, etc.

iii) Construir una nueva forma de sociabilidad, en donde lo fundamental es vivir con el grupo, alejarse de lo político para adentrarse en la complicidad de lo compartido al interior del colectivo (códigos estéticos, rituales, formas de escuchar música, lugares propios). La sociabilidad neotribal opone una actitud empática en donde las relaciones intersubjetivas se mueven en una cuestión de ambiente más que de contenidos específicos; de feeling más que de una racionalidad medios/fines. A diferencia del individuo que tiene una función en la sociedad, la persona juega un papel dentro del grupo.

iv) Necesidad de contraponer a la fragmentación y dispersión de lo global, la necesidad de espacios y momentos compartidos en los que se desarrolle una interacción fuerte pero no continua, un sentimiento de pertenencia y proximidad espacial. Ejemplos: eventos con un fuerte componente físico: baile, codearse, golpearse, beber, etc.

A partir de la formulación del enfoque neotribal algunos investigadores de juventud como Costa et al. (1996) y Feixá (1997) se aproximan a nuevos fenómenos vinculados a la subjetividad de los jóvenes urbanos, constituyendo el concepto de tribu urbana más una 
mirada que una conceptualización taxonómica de la diversidad de grupos juveniles. No se trata de nominar e identificar a un grupo particular de jóvenes sino de dar cuenta de un cierto ethos, forma de actuar y habitar el presente, que comparten diferentes formas de agrupación juvenil urbana como son pandillas, barras bravas de fútbol, y grupos de jóvenes que se agrupan en torno a estilos juveniles asociados a la cultura del rock. Pese a su diversidad social y de intereses, lo que compartirían estos grupos es una tendencia a potenciar las pulsiones gregarias y asociativas del joven como sujeto, una cierta defensa de intereses comunes por parte del grupo que estrecha vínculos gregarios basados en valores específicos, y la valoración de lo grupal como un ámbito para compartir experiencias y rituales, que generan y consolidan el sentido de pertenencia al grupo (Costa, Pérez y Tropea, 1996).

\section{a) Tribus urbanas en Chile: pandillas, barras y estilos juveniles}

En primer lugar, señalaremos que en nuestro país al igual que en otros el fenómeno de las «tribus urbanas» se ha hecho presente a partir de la relectura y proyección que han hecho la prensa y los medios televisivos de las experiencias de jóvenes de otros países (especialmente de la experiencia de España). Es así como los suplementos juveniles y programas de actualidad de televisión empiezan a hablar a mediados de los noventa de la existencia, fundamentalmente, en Santiago de Chile de un conjunto de jóvenes que se agrupan en verdaderas «tribus urbanas». Desde la perspectiva mediática la noción de «tribu urbana» deviene entonces en estereotipo que más que descubrir la subjetividad juvenil encubre las formas en que se desarrolla la socialidad entre los jóvenes.

Un segundo aspecto a considerar a la hora de explicar la emergencia de «tribus urbanas» en Chile es la modificación de las formas de habitar y vivir la ciudad producto de la absorción de las tendencias de globalización y consumo. En el caso de la ciudad de Santiago su situación no difiere de la de otras urbes del planeta. Producto de la globalización y masificación se produce una pérdida del valor del espacio local, cambian las condiciones de vida urbanas, esto se traduce en cambios en la vida cotidiana de las nuevas generaciones de jóvenes.

Por un lado, durante los noventa se produce un proceso de fuerte territorialización de las agrupaciones juveniles pertenecientes a 
sectores populares, constituyéndose una gran cantidad de pandillas juveniles que se agrupan fundamentalmente a nivel de las poblaciones y de los sectores más pobres de las comunas del sector norte y sur de Santiago. Estas pandillas y grupos de esquina se constituyen en torno a diferentes intereses en donde se incluye la adhesión a las barras bravas de los clubes de fútbol más populares de Chile como son el ColoColo y la Universidad de Chile, la identificación con una tendencia musical, fundamentalmente el rap y el hip-hop, o la identificación con códigos de la subcultura delincuencial.

Por otro lado, un circuito de jóvenes proveniente de comunas de sectores medios y adherentes a estilos juveniles como el punk, la new wave, que antes se agrupaba en torno a sus comunas va reconstruyendo su circuito en torno a la ocupación de espacios territoriales mayores ubicados en el sector centro de Santiago, estos jóvenes salen de sus circuitos locales para ocupar espacios céntricos como son la Plaza Italia y el Barrio Bellavista primero, y luego el sector del Parque Forestal ubicado atrás del Palacio de Bellas Artes. Lo mismo ocurre con adherentes a otras tendencias «musicales alternativas» como el tecno, el ambient quienes comienzan a agruparse en torno a espacios de consumo universal como son ciertos bares y discoteques del sector centro y poniente de Santiago.

Si bien la prensa ha tendido a confundir y a agrupar en un mismo rótulo, la existencia de diferentes formas de agrupación y construcción de grupos de referencia juvenil nominándolas como parte del fenómeno «tribus urbanas», nos parece interesante poner a prueba la validez de este concepto en el caso de agrupaciones juveniles que se constituyen en torno a espacios de consumo de la industria cultural juvenil. Es así como en el caso que presentamos a continuación, analizaremos de qué forma el «estilo alternativo» constituye un espacio de identificación homologable a una «tribu urbana». Para esto presentaremos nuestra experiencia de investigación con un segmento de jóvenes que se reúnen cotidianamente en torno al consumo cultural de música, estética y espacios urbanos como bares y discoteques en el sector poniente de Santiago.

A partir de nuestra investigación pudimos sintetizar la pluralidad de participantes de esta «tribu urbana» en a lo menos tres grupos de jóvenes. El primero constituido por los «antiguos» o los «pelaos», que congrega a jóvenes que se identifican con tendencias como la new wave, el tecno industrial y el punk, los que provienen de comunas populares de Santiago de Chile como San Miguel, La Cisterna, Reco- 
leta, Maipú, Independencia, Quinta Normal, etc. La autoidentificación de ellos como grupo, nace de un sentido de pertenencia a una comunidad de jóvenes, del compartir ciertos territorios. Son jóvenes que provienen de una misma comuna, de un mismo sector, de un mismo barrio.

Un segundo grupo constituido por estudiantes, que distingue en su interior a jóvenes que estudian carreras que son significadas como no convencionales, «alternativas». Nos referimos con esto a estudiantes de arte, teatro, diseño, publicidad, arquitectura tanto de universidades tradicionales como privadas o de diferentes institutos o academias. Por otro lado, y en oposición a los «estudiantes alternativos», encontramos un grupo de público flotante constituido por los jóvenes que estudian carreras que, en oposición a las artísticas, son vistas como «típicas» como son por ejemplo derecho, psicología, medicina, periodismo, etc.

Finalmente, encontramos un tercer grupo constituido por los «carreteros». ${ }^{2}$ Éstos son jóvenes que no trabajan en forma estable ni estudian sino que se dedican la mayor parte de su cotidiano a disfrutar de su «tiempo libre». Viven con sus padres, no estudian pero cuentan con una buena situación económica familiar, lo que les permite financiar sus «carretes», sin tener que trabajar.

Dentro de estos universos grupales, las mujeres se definen y reconocen como autónomas, manifestando un mayor nivel de individuación que los hombres. Ellas no se definen como parte de ningún grupo de referencia y desestiman las clasificaciones.

Una vez presentados los actores que forman parte de la tribu, haremos una breve caracterización del espacio físico y simbólico en donde estos jóvenes interactúan.

\section{LA DISCOTEQUE COMO TERRITORIO}

La Blondie, ${ }^{3}$ es una discoteque ubicada en el sector poniente de Santiago, al interior del Barrio Yungay, espacio en el que se congrega un grupo particular de jóvenes, hombres y mujeres de diferentes sectores de la ciudad, que semana a semana reviven en función de las

2 Nos referimos a jóvenes cuya cotidianeidad gira en torno a diferentes formas de ritualidad, que se caracterizan por el gasto festivo y el exceso.

3 La «Blondie» debe su nombre a un grupo musical inglés llamado Blondie, de ahí el nombre de la discoteque, blondie, que quiere decir blonda, rucia, ruciecita, teñida de rubio. 
fiestas que se desarrollan en la discoteque su pertenencia a un grupo de referencia juvenil que se autodenomina como «alternativo», que se caracteriza por el reciclaje y la mezcla de estilos y estéticas juveniles preexistentes como son el punk, la new wave y el tecno.

La discoteque abre sus puertas a mediados de 1993 instalándose en el sector de la Alameda, ${ }^{4}$ al interior de un centro comercial ubicado entre las calles Esperanza y Libertad que subsiste, marginal, desplazado primero por los caracoles y más recientemente por los mall. En su interior comparten espacio con ella, los más diversos locales: topless, picadas de colaciones y almuerzos, importadoras de ropa, peluquerías, imprentas, kioskos donde se hacen llaves, tiendas de ropa deportiva, etc.

La discoteque se encuentra ubicada exactamente donde antes se encontraba el Cine Alessandri, uno de los últimos «cines de barrio» que quedaban en el Santiago de los noventa donde se exhibían películas «eróticas» que veían los transeúntes que pasaban por la Alameda y los parroquianos del sector. Es aprovechando la estructura del cine abandonado que la Blondie construirá su estética minimalista marcada por mínimos arreglos que remarcan los conceptos de oscuridad y abandono. Parte siendo una discoteque orientada a un segmento de público juvenil masivo de corte más bien popular, que escucha música «dance», sólo para bailar, mas al poco tiempo sus antiguos dueños se asocian con un joven productor que había participado en las primeras «fiestas alternativas» realizadas en Chile, las Fiestas Spandex, el que cambia la propuesta de la discoteque dirigiéndola a un público selectivo que gusta de la «música alternativa». 5

El cambio de estética, más el uso de un circuito de difusión restringido, hace que en un primer momento a la fiesta tengan acceso sólo un grupo reducido de jóvenes que se identifican con la «música alternativa», este grupo estará constituido por un lado, por los «pe-

4 La Alameda Libertador Bernardo O’Higgins es la avenida central que atraviesa el centro de la ciudad de Santiago.

5 Entenderemos por «música alternativa» aquella música de rock que recogiendo estilos musicales de fines de los setenta y los ochenta como el punk, la new wave y el tecno, a comienzos de los noventa no era difundida en forma masiva por el circuito de las radios y la televisión chilenas. Con la masificación de los estilos, producto de la mayor difusión de la música a través de los canales de televisión por cable y el cambio de orientación de la programación de las radios FM, el término evolucionará del nominar un estilo particular de música a significar la exclusividad de un gusto musical restringido a un círculo de oyentes, el «gusto alternativo». 
laos», grupo de jóvenes urbanos que congrega diferentes tendencias provenientes de la subcultura del rock y por estudiantes de carreras vinculadas al teatro y al arte. Con el pasar del tiempo la Blondie irá ampliando su convocatoria y se producirá un flujo y reflujo de públicos y grupos «nuevos» y «antiguos» en la fiesta. En efecto, apoyada por una mayor cobertura de información y por afiches con llamativos diseños la Blondie se «abrirá» a un público que ve en ella un lugar de moda, un sitio «nuevo».

No obstante, así como la dimensión espacial aparece como una clave importante para comprender la subjetividad de los jóvenes, esta espacialidad se conjuga también con una temporalidad, noción de tiempo opuesta a lo cotidiano que encontramos reflejada en el evento de la fiesta. A continuación presentaremos una breve reconstrucción etnográfica de la temporalidad de la fiesta en donde se actualiza la pertenencia a esta tribu.

\section{EL TIEMPO DE LA TRIBU: LA «FIESTA ALTERNATIVA»}

Entrada la noche, cerca de las doce, el público empieza a hacer cola para entrar a la Blondie. Es sábado, día de una Old Wave, fiesta donde una vez al mes se rinde homenaje a un grupo de rock en particular. La fiesta ha sido avisada previamente a través de afiches que se reparten en diferentes sectores de la ciudad con semanas de anticipación. Porque la Old Wave es un evento, una fiesta que se prepara escuchando música, comprando en la ropa americana, «produciéndose», arreglando chaquetas, pantalones y vestidos en la casa propia o en la de amigos/as.

También se preparará la fiesta «carreteando» desde temprano en diferentes «bares alternativos», ${ }^{6}$ haciendo un recorrido por la ciudad hasta llegar a la fiesta. El tránsito y recorrido por bares constituirá un código previo a la fiesta, que es compartido por todos los que participan de ella. ${ }^{7}$

6 Entenderemos por «bares alternativos» aquellos que los jóvenes habitúes de la fiesta reivindican como diferentes a los «bares masivos», los pub. Se trata de los que ellos/as definen como «bares picantes», las "picás» donde lo «popular» es «descubierto» como novedad, la fritura, el pebre, el caldo, la marraqueta, la caña, el borgoña y el pipeño, el cacho y la chicha pasan a ser significantes de la diferencia.

$7 \quad$ Este recorrido es diferencial según sea el grupo o público al cual se pertenezca, los grupos que tenían una mayor antigüedad en relación con la Blon- 
Las puertas se han abierto media hora antes. Al interior de la discoteque resuena música más bien lenta como para crear ambiente. Poco a poco el público va bajando por las escaleras que conectan los tres pisos. En su interior la discoteque conserva la estructura del cine. La entrada seguida de una larga escalera da a un primer nivel en donde se encuentran los baños de hombres y mujeres, espacio que con el correr de la noche se constituirá en un lugar de desorden, de arreglos y encuentros, de comentarios y de «atinadas» entre jóvenes de ambos sexos.

Más abajo, en un nivel intermedio, encontramos un entrepiso, donde se encuentran algunos banquillos rectangulares de cuero negro de los tiempos del cine, espacio siempre ocupado por parejas de jóvenes vestidos/as de negro. Finalmente, bajando por la escalera llegamos al último piso, que una pared divide en dos espacios diferenciados, primero una sala pequeña donde se encuentra el guardarropas y luego la pista de baile.

La sala es el antiguo hall del cine, que dependiendo la fiesta se transforma en lugar de estar o en pista de baile improvisada. La estética es oscura, como en todo el trayecto, la luz de neón es tenue e indirecta, de un color azulado que remarca las sombras. En general al espacio se le introducen arreglos mínimos, no se busca disimular el deterioro del sitio sino remarcarlo con su olor a humo, a humedad convirtiendo la decadencia y el abandono del lugar en parte del ambiente de la fiesta. La Blondie se resistirá a ser vista sólo como una discoteque, sino que buscará mantener la ambivalencia del lugar abandonado donde todo está en penumbra y es difuso, donde pueden coexistir la intimidad y el anonimato.

A la sala principal se llega por dos entradas laterales que corresponden a las antiguas entradas del Alessandri. En un primer nivel se encuentra el bar, constituido por un mesón largo que atraviesa la sala de costado a costado. Bajando unas escalinatas se encuentra una amplia pista de baile, que aprovecha el espacio donde antes estaban las butacas del cine. Al fondo de la pista se encontrará una tarima rectangular de madera que sirve tanto de escenario para bailar como

die y la fiesta realizaban hasta fines de 1997, un circuito que tenía como punto de inicio el «Galindo» bar ubicado en Dardignac, en Bellavista, para después ir al 777 (Alameda con San Antonio) y esperar la fiesta en el «Huaso Carlos», ubicado en la calle Romero justamente a dos cuadras de la Blondie. Otros recorridos se iniciaban en las «Lanzas» o en el «Dante» de Plaza Ñuñoa, para después conectarse con el circuito anterior. 
para que las bandas toquen cuando se hacen recitales de rock. Detrás del escenario un telón reemplaza la pantalla, en el se proyectan clips, películas, animaciones japonesas, videos antiguos y nuevos que se conjugan con la música.

La luces blancas y de colores oscilan, la música se torna más bailable y la gente comienza a llegar, hombres y mujeres solos/as y en grupos de a cuatro o cinco. También llegan parejas. La mayoría comparte una misma estética oscura marcada por el color negro. Los hombres, los «pelaos» de bototos, pantalón de cuero, y chaqueta o una polera negra sin mangas. Otros ocupan pantalón negro y camisas blancas con vuelos, muchos aros y algunos pocos boinas. Sus cortes de pelo son cortos a los costados, con un pequeño jopo que destaca en la frente. Los más «producidos» ocupan maquillaje delineando sus ojos de negro. Otro grupo de hombres más minoritario, viste con más colores, con camisas naranjas, celestes o amarillas que empiezan a estar de moda, las que contrastan con el negro.

Las mujeres, se visten de forma más llamativa, ocupan abrigos de piel, faldas cortas y faldas largas, medias negras, rojas y verdes con motivos, con portaligas al descubierto. Camisas de seda de colores intensos, azules y rojos. Algunas de pelos cortos, otras con melenas, algunas con pelos teñidos de color rojo, otras con aros en la nariz y pinches en el pelo.

En general, no se trata de vestimentas caras o «de marca» si no de ropa reciclada de la «ropa americana». ${ }^{8}$ Sólo los/as más pudientes se visten con ropa de tienda que tratará de imitar el desgaste de la «ropa usada».

El costo de la entrada es bajo comparado con la media de las discoteques que duplican o triplican su valor, la entrada general cuesta $\$ 2500$ pesos; para estudiantes sólo $\$ 1500 .{ }^{9}$ Muchos de los jóvenes entran gratis porque tienen amigos, o son conocidos en el «ambiente» por lo que les hacen precio.

La «Old Wave» empieza el sábado para terminar el domingo teniendo una duración de más de ocho horas ininterrumpidas desde que se abren las puertas de la discoteque a las $23: 30$ y se cierran a las

8 Entendiendo la «ropa americana», como vestimenta de segunda mano que se vende al por mayor en locales como los ubicados en Calle Bandera o en los «Mercados Persa». La estética de la «ropa usada» se opondrá a la de la ropa de «moda» comprada en la tienda o en el mall, ropa sin uso, y a la estética juvenil universal del blue jeans y la polera o camisa.

$9 \quad$ Hablamos de un valor aproximado que fluctúa entre los 3 y 6 dólares. 
7:00 de la mañana. Es así como los y las jóvenes «alternativos» más devotos entran a la discoteque de noche y salen de día.

Los cubos de baile se convierten junto con la pantalla en centro de atención de la fiesta. En ellos convergen las luces de la discoteque, que iluminan a los que bailan de forma más llamativa que son los que visten con los looks más «alternativos». No se trata de ropas ostentosas sino de una estética hecha en base a la ropa americana o de segunda mano. En los cubos los y las jóvenes lucen sus vestimentas oscuras, bailando con diferente estilo según sea la música predominante.

En efecto, así como la estética adquiere un rol central, el bailar constituye un código implícito. Donde se ponen en juego una serie de elementos, como son los niveles de cercanía y proximidad con el «otro». Si el código de la fiesta juvenil masiva es bailar con la pareja, en el bailar «alternativo» se pone énfasis en la distancia, se baila con todos y con nadie en particular. También el bailar expresa estados de ánimo, hay un bailar hacia fuera y un bailar hacia adentro más introspectivo, un fusionarse y un «borrarse» en la masa.

A través de toda la noche se irán sucediendo espaciadamente diferentes temas del grupo en inglés escogido como centro de este homenaje colectivo. Junto a la música se acompañará la imagen del o los cantantes proyectada en una pantalla ubicada al fondo de la discoteque. Dependiendo el nivel de fervor e identificación de las y los jóvenes con el grupo o el/la cantante, el baile sufrirá un cambio, el bailar solo/a se convertirá en bailar con el/la «estrella de rock», es así como uno de los momentos de máxima intensidad de las Old Wave es cuando ya entrada la madrugada, como a las tres de la mañana, los «pelaos» bailan con la imagen de Siouxie o de Morrisey. ${ }^{10} \mathrm{El}$ baile se transforma en un baile virtual con un «otro imaginario» que proyectado en la pantalla se transforma en el espejo del/la joven. Cuando Siouxie aparece en escena es un bailar fuerte, campante, hacia fuera, más bien en grupo. Con Morrisey el baile es suave y delicado, es un

10 Asistimos a diferentes Old Wave de distintos grupos y cantantes de la «new wave» de los ochenta, como son Siouxie \& The Banshees, Morrisey y The Smiths, Boy George y Culture Club entre otros. Los «personajes» más importantes para los y las participantes de la fiesta son los Siouxie y Morrisey, que conjugan dos modelos de género que invierten las características culturalmente asociadas a lo femenino y lo masculino, Siouxie muestra una imagen de mujer masculinizada y Morrisey juega con la indefinición entre lo masculino y lo femenino. 
guiño entre dos, se baila sólo con él.

Otro hito dentro de la fiesta será la interrupción del baile por «performances» realizadas por jóvenes actores, malabaristas y tragafuegos que realizan un espectáculo que produce un corte en la cotidianeidad de la fiesta, para reiniciar el baile con mayor fuerza e intensidad.

Pasada las tres de la mañana sólo quedarán en la fiesta los y las jóvenes más «fieles», los que vienen a pie solos/as o en grupos, ya que los jóvenes con auto ya se habrán retirado. Ya a las siete de la mañana cuando se encienden las luces sólo quedarán un grupo de unos treinta jóvenes que empiezan a retirarse para tomar la micro o el metro en la estación Unión Latinoamericana, otros/as continuarán la fiesta en los bares y restaurantes que ya están abiertos en la Alameda o en el sector de Estación Central.

\section{LOS CÓDIGOS DE LA TRIBU}

Una vez descritas las dimensiones espaciales y temporales en que se constituye la vivencia de este grupo de jóvenes, expondremos lo que a nuestro juicio son los códigos subyacentes a la pertenencia e identificación juvenil con esta «tribu alternativa». Para dar cuenta de estos niveles de significación nos apoyaremos en los testimonios de algunos de nuestros/as entrevistados/as.

\section{a) Consumo de territorios y recorridos «alternativos»}

Uno de los código inherentes a la construcción de identidad de esta tribu, es la forma en que los y las jóvenes involucrados construyen puentes y vinculaciones entre su cultura juvenil local y la cultura global recepcionando y apropiándose de espacios de consumo. En el caso del consumo del bar y la discoteque encontramos que a pesar de ser estos espacios universales y masivos, se da una apropiación distintiva de éstos como «territorios simbólicos». Recordemos que la posesión y uso del espacio urbano como territorio por parte de lo que se ha dado por denominar «tribus urbanas» se sitúa tanto a nivel físico como simbólico. Cuando un joven habla de «su» bar o «su» discoteque su identificación con el espacio estará operando tanto a nivel afectivo como posesivo, siendo ésta una expresión de autoafirmación (Costa, Pérez Tornero y Tropea, 1996). 
En efecto en ambos casos, la relación de los y las jóvenes con el espacio va más allá de una construcción de identidad homogénea y masiva como es la de un público, sino que tiene que ver con otros niveles de identidad asociándose la apropiación simbólica del territorio con la pertenencia a estratos sociales y géneros.

En el bar se restablece el orden cotidiano de las relaciones, es lugar de encuentro y reafirmación de identidades previas donde se establece una presencia no sujeta a la mediación de la estética y la imagen, el bar es un espacio de reconocimiento, donde las identidades colectivas tienden a reafirmarse y fijarse más que a disolverse. En contraposición al bar, el sentido que se le da a la ocupación de la discoteque aparece en disputa dependiendo el grupo de consumo. Por un lado para los jóvenes de sectores medios y altos, la Blondie es significada como un lugar de representación, donde las identidades previas de clase, de grupo y género parecen estar en fuga, donde se busca disolver el orden cotidiano y "perderse en compañía de otros». Por otro, para los «pelaos», la Blondie es el territorio simbólico y el espacio ritual donde se actualiza la identidad del grupo que ocupa la discoteque como un espacio cargado de significación, ya que es tanto un espacio de pertenencia como de representación del grupo, siendo el lugar en donde el grupo manifiesta su existencia social exhibiéndose ante los demás.

Por otro lado, fuerte identificación con un tipo de música y estética en la que se funda la pertenencia a la «tribu», implica que para conseguir la música y la estética adecuada exista la experiencia de un recorrido por determinados espacios de consumo que para los «jóvenes alternativos» aparecen como espacios marginales en relación con los espacios de consumo del joven «común y corriente» que no pertenece al «circuito alternativo».

En efecto, los «pelaos» establecen relaciones de fuerte identificación con los bienes que consumen, para ellos su música y vestimenta tiene un sentido colectivo, son bienes-signo que «significan» al grupo, que identifican a los que pertenecen a su «onda». Para escuchar su música y crear su estética, requieren de un recorrido por espacios de consumo marginales al consumo de la tienda comercial, del shopping o el mall. Lugares como el Persa Bio-Bío, Franklin, las tiendas de ropa americana de Bandera van significando una apropiación que pone acento en un cierto territorio en donde si bien se realiza una transacción monetaria, el énfasis está puesto en reciclar lo ya usado, lo «carreteado», lo que tiene experiencia y calle. 
Los otros grupos «alternativos», estudiantes y «carreteros» manifiestan un consumo mucho más desterritorializado cuyos elementos son de primera mano y no cuentan con la marca y distinción de lo usado - a lo más parecen usados, simulan la experiencia del uso-. Por otro lado, estos jóvenes tienen mayor acceso económico a una estética que se hace masiva, que hoy la pueden tener tanto en el Persa como en la tienda comercial del mall. Su relación con el consumo puede definirse como de tránsito, por relaciones de identificación inestables que van de lo individual a lo colectivo, del núcleo de la persona al grupo. Ellos recorren looks, estilos musicales y espacios de consumo marginales y centrales en busca de una identidad que no encuentran en otros espacios como la familia, la universidad, los pares, etc.

Este choque entre las subjetividades que unos y otros asocian al consumo de bienes se agudiza con la masificación y banalización de la estética «alternativa». El significado de lo «alternativo» transita del ámbito de la experiencia, de lo vivido «por otros» que connota la ropa usada, al del significante de un consumo esterilizado que simula tener experiencia.

\section{b) La estética o el juego con las representaciones de lo femenino y masculino}

La «tribu alternativa» es un espacio/lugar en donde las relaciones se constituyen y se construyen a través de las formas. Es así como los códigos que predominan no son los discursivos, como la conversación, sino los de la representación del cuerpo, a través de la imagen. La «actuación» del cuerpo a través del uso de determinados signos adquiere centralidad. A través del cuerpo se redistribuyen una serie de significantes de orígenes distintos y contrapuestos. Se combinan diferentes estilos de vestimenta, colores fuertes con colores oscuros, corte de pelo punk con camisa con vuelos. La originalidad consiste en la combinación de diferentes temporalidades y orígenes, lo retro con lo actual.

Lo central en el «estilo Blondie» es el reciclaje, no se produce algo nuevo sino que se recombina lo antiguo con lo nuevo en un «bricollage», que mezcla diferentes estilos. A través del baile y la estética se muestra en forma agresiva a los «otros» una forma de ser que es diferente a la convencional, no se trata de mostrar una historia o un significado colectivo a través de la ropa y el cuerpo, sino de una recombinación de signos al servicio de una puesta en escena individual: 
...y llegué y eso fue lo que me llamó la atención que la gente va a bailar al Blondie y también a mostrar pintas cachai, también a que los miren lo extraños que son, pero también súper agresivamente, o sea onda, yo soy súper extraño y yo tengo mi onda y no te pesco... (Paula, 20 años, estudiante de teatro).

Esta recombinación de signos no sólo rompe con las fronteras temporales, diferentes modas que se reciclan en un look personal, sino que también juega con las representaciones tradicionales de la diferencia sexual:

...siempre pasan, transitan a mi lado mujeres, no masculinas pero con caras muy andróginas, pelos cortos, el cabello corto, ropas ajustadas pero que no delatan tampoco una identidad sexual femenina, lo mismo los hombres, la instancia de maquillaje en los hombres, cuando los hombres se maquillan, puede ser una carga estética, un permiso estético pero también acarrea una connotación sexual... (Andrea, 21 años, estudiante de diseño gráfico).

La construcción de una estética, se transforma en un espacio lúdico en donde se juega con los límites de la distinción sexual. Paralelo al cruce por diferentes estéticas, se hace un recorrido por diferentes representaciones de la sexualidad y de lo femenino y masculino. El juego con las formas, permite experimentar, buscar nuevas formas de representarse ante sí y ante los demás. Lo que importa es el juego en sí mismo, el recorrido por las formas, no su contenido. No se trata de ser, sino representarse para el/la «otro/otra» virtual al que no se conoce pero se sabe está mirando.

El encanto que ejerce este juego de transgresión, proviene más de la vacilación sexual, que de la atracción hacia un mismo sexo. Se trata de mostrar, sugerir la «otra» sexualidad que se encuentra en uno "mismo», pero éste es un ejercicio de exterioridad que debe quedarse en la forma, lo «otro» sólo se muestra, no debe trascender el nivel de las formas. La invitación de la fiesta es a jugar un juego donde se pone en escena una "sexualidad virtual», se juega con los límites sexuales sin llegar a trasponerlos. No obstante se corre el riesgo de que lo efímero y transitorio adquiera un sentido permanente, el «peligro» está en que el goce se transforme en placer: ${ }^{11}$

11 Entendemos la oposición goce/placer, en relación a que uno de los términos, el goce, representa el gusto por lo efímero, lo fugaz de la forma, en oposición al placer que representa la fijación del deseo como algo permanente, 
...el problema está en conocer, en conocer está el peligro, de repente conocís una volá media extraña y te quedó gustando y se te da vuelta el paraguas y es pesado... conocís mucho y te queda gustando... (Marcos, 21 años, se define como «tecno»).

En síntesis, a través del juego con los signos y las formas, las nociones de lo masculino y femenino pasan a ser reducidas a signos que son recombinados al servicio de la seducción. Entonces lo que importa no es el sexo sino el juego, la parodia mediante la sobresignificación del sexo, la parodia de la feminidad y la masculinidad tal como los hombres y mujeres la imaginan. Es esa posibilidad de ser/parecer diferente la que atrae y motiva la representación de formas de ser que escapan al orden de lo cotidiano. Si el bar es el lugar de encuentro cotidiano donde se reafirma la pertenencia a un orden, la fiesta es un espacio de fuga donde se deconstruyen las identidades preexistentes dando paso a la representación de otras identidades posibles o imaginarias:

...yo una vez vi una mina que estaba dentro de la Blondie con una faldita cortísima y unos tacones altos y un pelo... se veía espectacular la mina, es que ella era muy bonita y yo me preguntaba... esta mina tiene que andar sola... iy andaba sola cachai...!, entonces yo dije esta mina tiene que andar en auto, porque yo de partida ni cagando me voy en micro pa'mi casa, y de repente la vi salir, porque yo salí con ella y nos juntamos en la micro y la mina andaba con una mochila de este porte y con unos pantalones súper sueltos y con una chaleca larga cachai, entonces la loca se disfrazaba pa'entrar, ¡lo podís creer!... y hay ene minas así, de que llegan, tu entrai al baño y se están pintando, se están arreglando los ojos, cambian su look pa'entrar y así lo viven... (Ana, 21 años, estudiante de teatro).

\section{c) La intensidad y la energía del bailar}

Uno de los motivos recurrentes que atraviesa los diferentes comportamientos de los grupos de jóvenes que van a la Blondie es el modo de bailar. El baile y el cómo se baila forman parte de los códigos para ser «admitido» como parte de la fiesta. Se privilegia el bailar solo o en grupo al bailar en parejas. La acción de bailar solo/a es significada de forma distinta por hombres y mujeres.

Para los «pelaos» el bailar tiene una vinculación con la pertenencia a un grupo de pares, de amigos o a un grupo mayor que comparte el gusto por un mismo estilo musical:

que no es sólo forma sino que cuenta con un contenido, referente o discurso que le da sentido. 
Voy por estar con mi grupo de amigos y escuchar la música con mi grupo de amigos, en un lado donde la podís bailar y podís estar relajado... en el fondo es un lugar para ir a divertirse pero con la diferencia que es pa'gente que piensa distinto, o sea gente que busca otras cosas, otro tipo de música, otra propuesta... (Marcos, 21 años, se define como «tecno»).

Para los «nuevos», su relación con el baile tiene relación con el «descubrimiento» de nuevas formas de relacionarse consigo mismos en el plano de la fiesta, no se requiere estar acompañado de una pareja sino que se puede disfrutar solo:

...yo por lo menos antes cuando estaba bailando con una mina en una discoteque la pasaba mal, amurrado, así escuchando música, ahora la paso súper bien aunque no esté con una mina, bailando solo, escuchando la música, por lo general me gusta harto la música que tocan, ése es el principal motivo porque voy... (Matías, 20 años, estudiante de psicología).

Para las «chicas alternativas» el baile es significado como un espacio nuevo de libertad, donde no existe la obligación de estar bailando para el «otro», el pololo o la pareja ocasional, se baila para sí no para los demás. El baile se puede convertir en un «territorio personal», en el que no hay obligación de bailar con nadie ni hay límites prefijados. Se da la libertad de bailar sola y a la vez con otros, sin el «deber ser» de estar en una situación de seducción con un hombre y sin tener que estar esperando que «te saquen» a bailar:

...yo voy a bailar y onda a relajarme a escuchar la música que te gusta, a darte las vueltas que querai, que nadie te mire, que nadie te toque, cachai... una cosa como que no están, como que no se están engrupiendo a una mina, como que no están conversando, sino que van a bailar, primera cosa, como que van a bailar, la gente no va a hacer vida social... (Marcela, 19 años, estudiante de arquitectura).

Otra significación recurrente en las mujeres es la de vivir la fiesta y el baile como un espacio individual de catarsis, como un lugar donde se consume una gran cantidad de energía:

...yo cuando voy, voy a bailar, voy a bailar a sacarme la cresta bailando, a mí me gusta matarme bailando, yo te digo cuando yo voy a la Blondie yo digo me voy y estoy cinco horas bailando, yo me puedo quedar hasta las ocho de la mañana... (Paula, 20 años, estudiante de teatro).

Se ve en el baile una forma de descargar en forma expresiva y en un espacio no cotidiano, una acumulación de energía de la que el 
orden racional-productivo no da cuenta. Al igual que el efecto de algunas drogas, pasado el efecto catártico de la fiesta, se produce un contraste al tener que volver al orden cotidiano. Por otro lado, en el disfrutar el baile hay una búsqueda de sentido, para lo que viene después de la fiesta, la relación con la cotidianeidad, del «resto de la semana». Para algunas jóvenes el costo de la fiesta es el «achaque», el «bajón» del tener que despertar para tener que volver el lunes al mundo de las obligaciones y del deber ser (como estudiante, como trabajador/a):

\begin{abstract}
...como que al otro día venís con todo el achaque... igual se da caleta esa cuestión, tú salís, carretiai toda la noche, de repente te drogai y al otro día como que te viene todo el achaque, como que al otro día te levantai como a la una, como que andai desenchufada, es como «el otro día», te juro yo lo paso súper bien pero me da lata pensar en el otro día, como que vai a despertar toda, toda estrujada como que fuiste feliz por una noche y al otro día como que seguís la vida... (Marcela, 19 años, estudiante de arquitectura).
\end{abstract}

\title{
d) La fragilidad de la mirada
}

Otro código compartido e internalizado por los participantes de la «tribu alternativa» es el de la actitud individualista. Para los jóvenes universitarios la individualidad se expresa, en una actitud que ven en los «antiguos», en los "pelaos», de no interactuar, «no pescar», a los demás participantes de la fiesta. El «no pescar» lo representan en la mirada.

...te miran, te miran pero si te miran te miran de reojo por eso te digo también se contrapone... que tú no querís mirar y no querís que te miren y querís pasar inadvertido, pero en el fondo te vestís onda para llamar la atención, bailai para llamar la atención... (Elena, 27 años, estudiante de arte).

El juego de la mirada transita entre dos polos: el querer mirar y que no te miren, deseo romántico y el no mirar y que te miren, deseo de reconocimiento. Hay un doble juego, se trata de ser y no ser atrapado por la mirada del «otro».

...igual es súper impersonal, por eso te digo que esa cuestión de pasar inadvertido yo encuentro que igual para la gente es una contraposición [sic], porque por un lado pasai inadvertido bailando solo, bailando en una esquina, bailando piola, cachai, pero tú te vestís bien, ponte tú si va una mina de plateado que baila sola igual no va a pasar inadvertida, entonces igual es como una cosa rara... (Marcela, 19 años, estudiante de arquitectura). 
El «no pesco» aparte de ser una actitud individual es visto como reflejo de una conducta generalizada fuera del ámbito de la fiesta. En ese sentido el «no pescar» es un código que tiene relación con el «afuera», no se trata de un quiebre con el orden cotidiano sino de una muestra y un reflejo, de un «estado de ánimo» generalizado, a nivel social y generacional:

...se ve en el baile, la manera de bailar y la manera de moverse, pero eso está de moda no solamente ahí, es como todo un fenómeno como el no pescar a la gente, como que no estás con nada, el no tener nada que decir, no sé si será tan así, igual lo veo como una cosa de fenómeno más social, o sea estamos en una época en donde como que nada importa mucho... (Elena, 27 años, estudiante de arte).

\section{e) La uniformación en la masa}

La fiesta es percibida por la tribu como un espacio donde la individualidad irrumpe con violencia. La exterioridad de la fiesta genera un efecto de frialdad y de superficie, se está para ser visto no para ser hablado. La carencia de una comunidad explicitada en el lenguaje hace que en momentos de extrema individualidad parezcan desaparecer los vínculos sociales entre los sujetos, el individualismo extremo despersonaliza. Para un grupo considerable de participantes, la fiesta es vivida como un espacio que es valorado ambigüamente como espacio de libertad y de inversión del orden cotidiano, pero también es un espacio de uniformación en la masa:

...no sé antes las fiestas eran como más, como que tú estabai más metido con la gente, últimamente como que las fiestas son como súper separatistas, individuales, muy individualistas, o sea tú vai ahí y eres un individuo, no parte de un grupo, eres como, son un montón de individuos los huevones, cachai, como una masa de individuos... si lo ves de lejos es como una masa de gente negra, de negro cachai, pero si tú los veís a ellos son como cada uno, solos, por sí solos, están todos solos ahí... a menos que... es como, como todo el mundo baila bien, solo, sin que te molesten, sin estar preocupado del que está al lado... (Elena, 27 años, estudiante de arte).

Se compara la fiesta juvenil de «antes» con la de «ahora», el desarrollo de una extrema individualidad marcaría un quiebre en la forma de relacionarse entre-jóvenes de diferentes generaciones. Para los de una generación mayor (de los ochenta) se trata una individualidad que se expande con el efecto de la masa, constituyéndose en una «individualidad colectiva», la representación extremadamente indivi- 
dual de signos identitarios logra un efecto contrario, el individuo se funde y se con-funde en la masa, la estética que antes diferenciaba, uniformiza.

\section{CONCLUSIONES}

Si resumimos las características de la agrupación juvenil que observamos encontramos que se hacen presente algunas características que vinculan a los «jóvenes alternativos» con las tribus urbanas.

Por un lado, nos encontramos que para cada uno de los grupos y jóvenes que participan de la tribu, el construir una imagen y un conjunto de actitudes y/o comportamientos en relación a ella, constituye una estrategia identitaria que permite salir del anonimato y de la masa, sentirse parte a lo menos una vez a la semana de una tribu, de un «ambiente», que otorga un sentido de identidad que se ve reafirmado y reforzado colectivamente. Esto permite a los y las jóvenes sentirse diferentes, diferenciándose de la imagen de un joven normal. El pertenecer a la tribu constituye una opción por esencializar ciertos aspectos identitarios, opción excesiva, ya que quiere programadamente excederse, superar las limitaciones, las reglas y comportamientos que la sociedad dominante y uniformadora impone a los jóvenes. En el caso de esta tribu, el estilo juvenil «alternativo» se fundamenta en la construcción de un conjunto de reglas específicas y diferenciadoras respecto a la ocupación y consumo de espacios y bienes a partir de los cuales el joven «alternativo» se siente dotado de un principio de identidad personal, que es respaldo por la pertenencia al grupo.

Por otro lado, un tema que aparece latente en el acercamiento a grupos juveniles urbanos como el expuesto, es la tensión que empieza a producirse entre un espacio local juvenil apropiable y un espacio juvenil global masivo que diluye la construcción de identidades territoriales sólidas. La dispersión y complejidad que generan los procesos de globalización provoca el surgimiento y la necesidad de contar con espacios que puedan ser compartidos por los jóvenes, respetando las reglas que constituyen su forma de construir identidad. Es así como la Blondie como territorio simbólico se transforma en un espacio en disputa entre los que establecen una relación colectiva y los que establecen una relación sólo comercial con él. El tema de la apropiación de estos espacios de consumo juvenil nos plantea una reflexión sobre los derechos que tienen los y las jóvenes a contar con un espacio apropiable que no sea agredido y limitado por otros jóvenes o adultos. 
Así como lo territorial aparece como un código importante, la temporalidad de la fiesta nos muestra el ritmo y la intensidad con que estos jóvenes viven su presente al interior del grupo. Se trata de una contraposición de tiempos, el tiempo de ocio opuesto al tiempo productivo que marca lo cotidiano. En ese sentido la fiesta se constituye en el evento extraordinario que da sentido a lo cotidiano, se la espera y se la prepara con anticipación a través de arreglos estéticos y rituales urbanos. Dentro de ella, en el baile se desahoga la energía subterránea que se encuentra aprisionada por la rutina y la cotidianeidad de lo urbano.

Otro tema, que aparece presente en este grupo y que coincide con los planteamientos neotribales, es el de la tensión entre individuo/masa, y entre lo colectivo y lo individual. Esta tensión la expresamos en el fenómeno que denominamos «individualidad colectiva» que nos permite señalar que el proceso de tribalización que se constituye en torno a la discoteque Blondie se fundamenta en una contradictoria estrategia de los y las jóvenes que se ven atrapados en su juego de identidad, ya que plantean en torno a la estética una construcción de identidad que quiere escapar de la uniformidad de lo masivo, pero termina vistiendo un uniforme, constituyendo masa.

Por otro lado, muchas veces la participación que se tiene dentro de la «tribu» no busca plasmarse en un compromiso con el «otro» fuera del marco del evento de fin de semana. Esto lo encontramos simbolizado en la «mirada oblicua» que "pesca» y «no pesca», se compromete y no se compromete a la vez con lo que está pasando a su alrededor. Retomando lo planteado por Maffesoli, respecto a la socialidad juvenil, «se trata menos de agregarse a una banda, a una familia o a una comunidad que de revolotear de un grupo a otro. [...] En efecto, en contra de la estabilidad inducida por el tribalismo clásico, el neotribalismo se caracteriza por la fluidez, las convocatorias puntuales y la dispersión» (Maffessoli, 1990:140).

Otra propiedad que aparece presente en este grupo, es la de sujetos y grupos que se expresan en la fiesta como espacio de juego y búsqueda, tránsito y recorrido mediatizado por los códigos de la representación. Al no tener discurso, las prácticas no se fijan en un contenido único. En la Blondie se juega con las representaciones sexuales y de género, ironizándolas, sacándolas de su contenido discursivo, de su sentido, sobreexponiéndolas a la mirada cómplice del otro/a. Este juego con los límites contrasta con la resignificación que se hace de los modelos de género culturalmente construidos, es así como lo «an- 
drógino» coexiste con la representación exagerada de lo tradicionalmente masculino y femenino.

Este ethos juvenil, expresado en la ritualidad de la fiesta plasma una forma de construir identidad y de dar sentido a la vida desde el presente. Como respuesta a procesos de modernización excluyente, y a la disolución de los espacios de integración que la sociedad ofrece a los jóvenes, un grupo significativo de ellos construye una nueva «estructura de comunicación», que no se basa en los códigos de la generación anterior (identidad centrada en la política y el discurso), sino que se identifica con una sensibilidad, que se caracteriza por su ritualidad, por su capacidad de crear vínculos a partir del compartir la experiencia del rito, en este caso la experiencia de pertenecer de una u otra forma a una tribu.

El nexo que se establecería entre los diferentes jóvenes estaría dado por compartir una misma experiencia ritual a partir de ésta se crearía el vínculo de pertenecer a una misma comunidad que se constituye y se construye para algunos mes a mes, para otros semana a semana en el acto mismo de estar juntos en-el-rito de compartir música, baile, estética, territorios y recorridos.

\section{BIBLIOGRAFÍA}

BOURDIEU, PIERRE (1990): Sociología y cultura. México: Grijalbo.

CONTRERAS, DANIEL (1996): "Sujeto juvenil y espacios rituales de identidad: el caso del 'carrete’». Proposiciones N²7. Santiago: Ediciones SUR.

COSta Pere-Oriol; José Manuel Pérez Tornero y FABio TROPEA (1996): Tribus urbanas. El ansia de identidad juvenil: entre el culto a la imagen y la autoafirmación a través de la violencia. Barcelona: Paidós.

FEIXÁ, CARLES (1997): De jóvenes, bandas y tribus. Antropología de la juventud. Barcelona: Ariel.

MAFFeSOLI, Michel (1990): El tiempo de las tribus. Barcelona: Icaria.

MARgUlis, MARIO y MARCELO URRESTI (1996) «La construcción social de la condición de juventud». En CUBIDES, LAVERDE y VALDERRAMA (compiladores): Viviendo a toda. Jóvenes, territorios culturales y nuevas sensibilidades. Santafé de Bogotá: Siglo del Hombre Editores y Fundación Universidad Cen- 
tral.

MATUS, CHRISTIAN (1995a) «Cultura, rock y modernización: una mirada desde una sensibilidad juvenil». Santiago: Escuela de Antropología, Universidad de Chile (mimeo).

(1995b): «Alternativo/Masivo. Una mirada de generación y género al consumo cultural de jóvenes de sectores medios». Tesis de Título de Antropólogo Social, Escuela de Antropología, Facultad de Ciencias Sociales, Universidad de Chile.

SALINAS, FRESIA (1999): «En el borde del sistema: las pandillas juveniles». Revista de Antropología Social Austerra N ${ }^{\circ} 1$. Santiago: Escuela de Antropología Social, Universidad Bolivariana.

\section{GLOSARIO}

ATINAR: Relación ocasional que no implica compromiso entre jóvenes.

ATINADA: Relación ocasional entre jóvenes. Su rango de involucración es impreciso, va desde caricias y besos hasta concretar una relación sexual.

CARRETE: Espacio juvenil de fiesta, donde los jóvenes comparten en grupo el consumo ritual de música, droga, alcohol y otros bienes materiales y simbólicos.

CARRETEAR: Compartir un «carrete», un espacio festivo.

CARRETEADO: Trasnochado, enfiestado «andar carreteado».// También con mucho uso, gastado por el uso.

CARRETEROS: Jóvenes que se caracterizan por dedicarle una gran cantidad de tiempo a espacios festivos juveniles.

LOS PELAOS: Grupo de referencia juvenil que agrupa a new waves, darks, tecno industriales y otras tendencias del postpunk. Se les nomina así por sus particulares cortes de pelo.

MICRO: transporte de locomoción colectiva.

MÚSICA DANCE: música bailable de circuito comercial.

MÚSICA ALTERNATIVA: música que agrupa las diferentes tendencias del postpunk como la new wave, el tecno industrial, el dark y otros estilos musicales. Se la opone a la música bailable comercial.

NO PESCAR: no considerar al otro, no dar atención ni importancia.

ONDA: estilo, tendencia.

PICADA: bar, restaurante, de origen popular caracterizado por la venta 
a bajo precio de gran cantidad de platos y licores considerados tradicionales.

PRODUCIRSE: arreglarse, crear una estética y una puesta en escena para ir a la fiesta o el «carrete».

PESCAR: considerar, dar atención a alguien; «pescarlo», incluirlo. 